\title{
Screening Patients with a Family History of Colorectal Cancer
}

\author{
Robert H. Fletcher, MD, MSc ${ }^{7,4}$, Rebecca Lobb, MPH', Mark R. Bauer, MD², \\ James Alan Kemp, MD, MPH ${ }^{2}$, Richard C. Palmer, DrPH ${ }^{3}$, Ken P. Kleinman, ScD', \\ Irina Miroshnik, $\mathrm{MS}^{\mathrm{l}}$, and Karen M. Emmons, $P h D^{3}$
}

'Department of Ambulatory Care and Prevention, Harvard Medical School, Harvard Pilgrim Health Care, and Harvard Vanguard Medical Associates, Boston, MA, USA; ${ }^{2}$ Harvard Vanguard Medical Associates, Boston, MA, USA; ${ }^{3}$ The Dana-Farber Cancer Institute, Boston, MA, USA; ${ }^{4} 208$ Boulder Bluff, Chapel Hill, NC 27516, USA.

OBJECTIVES: To compare screening practices and beliefs in patients with and without a clinically important family history.

DESIGN: We mailed a brief questionnaire asking about family history and a second, longer survey asking about knowledge of and beliefs about colorectal cancer to all respondents with a family history and a random sample of respondents without a family history of colorectal cancer. We reviewed electronic medical records for screening examinations and recording of family history.

PARTICIPANTS: One thousand eight hundred seventy of 6,807 randomly selected patients ages 35-55 years who had been continuously enrolled in a large multispecialty group practice for at least 5 years.

MEASUREMENTS: Recognition of increased risk, screening practices, and beliefs-all according to strength of family history and patient's age.

RESULTS: Nineteen percent of respondents reported a family history of colorectal cancer. In $11 \%$, this history was strong enough to warrant screening before age 50 years. However, only 39\% (95\% CI 36, 42) of respondents under the age of 50 years said they had been asked about family history and only $45 \%$ of those with a strong family history of colorectal cancer had been screened appropriately. Forty-six percent of patients with a strong family history did not know that they should be screened at a younger age than average risk people. Medical records mentioned family history of colorectal cancer in 59\% of patients reporting a family history.

CONCLUSIONS: More efforts are needed to translate information about family history of colorectal cancer into the care of patients.

KEY WORDS: family history; colorectal cancer; genetic; risk. DOI: $10.1007 / \mathrm{s} 11606-007-0135-2$

(C) 2007 Society of General Internal Medicine 2007;22:508-513

\section{INTRODUCTION}

Colorectal cancer is a leading cause of cancer death, both in the US and throughout the world. There is strong evidence that this cancer can be prevented and screening is recommended in clinical practice guidelines. ${ }^{1-3}$ However, screening rates are low. Only $57.3 \%$ of US adults were screened by currently recommended standards in $2004 .^{4}$

Family history is a major risk factor for colorectal cancer. Incidence is increased in relation to the number of family members with this cancer, whether they are first- or seconddegree relatives, and early age of onset. ${ }^{5-7}$ Clinical practice guidelines match the aggressiveness of screening recommendations to the strength of the family history ${ }^{3}$. However, little is known about how these recommendations have been implemented in the care of patients. ${ }^{8}$

We studied patients with a family history of colorectal cancer in a large multispecialty group practice and compared their care to that of patients without this family history. We describe the prevalence of family history according to its strength, whether family history was identified at a time when screening should have been started, and whether this knowledge led to appropriate screening. We also describe patients' beliefs and attitudes concerning family history in relation to their risk and screening experience.

\section{METHODS}

Design. We surveyed a random sample of patients about their family history of colorectal cancer, screening experiences, and demographic characteristics. We then sent a follow-up survey asking about attitudes, knowledge, and beliefs concerning colorectal cancer and the consequences of having a family member with this cancer. Finally, we reviewed electronic medical records to assess screening and agreement between patients' reports of family history and information in the medical records. This study was approved by the Committee for the Protection of Human Subjects at Harvard Pilgrim Health Care.

Setting. Our study took place at Harvard Vanguard Medical Associates (HVMA), a multispecialty group practice in the Greater Boston area that is responsible for the heath care of about 300,000 patients. At the time of the study, HVMA was comprised of 14 practices with 160 primary care physicians (for
Received August 11, 2006

Revised December 15, 2006

Accepted January 17, 2007

Published online February 8, 2007 


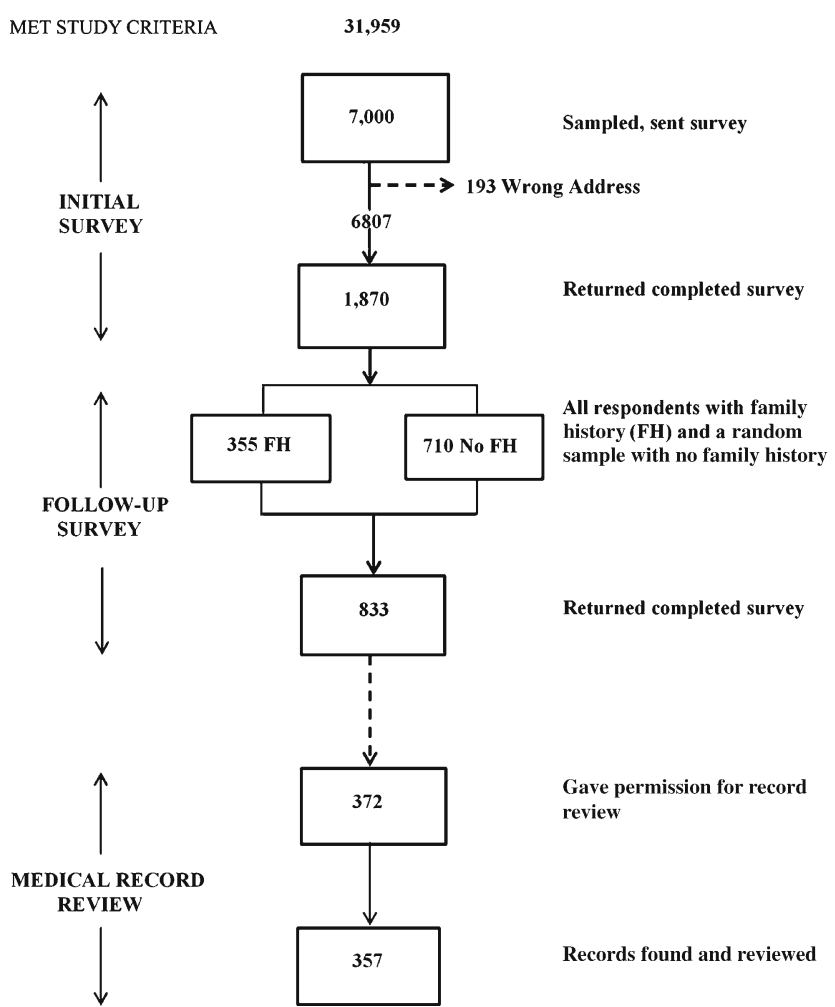

Figure 1. Sample selection and participation according to stage of the study.

care of adults, mostly general internists) who were responsible for initiating screening and 12 gastroenterologists. Primary and specialty care is integrated through shared electronic medical records, formulary, guidelines, email communications, physical proximity within practices, and administrative structure. Preventive health care has been a priority at HVMA since it was founded as a staff model HMO in 1969.

Population and Sample. As of January 1, 2004, 31,959 patients were 35-55 years old, continuously enrolled at HVMA for the past 5 years, insured by HVMA's main insurer (Harvard Pilgrim Health Care), and met the following criteria: no record of conditions that might have led to lower gastrointestinal endoscopy (such as intestinal cancer, inflammatory bowel disease, recent gastroenteritis or colitis, evidence of intestinal blood loss, or other disorders of the intestine); no conditions that might have precluded responding to the survey; no "sensitive" diagnoses (such as substance abuse or HIV infection); and not on a list of patients who had requested that they be excluded from all survey research at HVMA. We included patients $<40$ years old because some guidelines recommend that screening begin 10 years before onset in the family member and to provide a context for interpreting screening in increased risk patients. Sample selection and participation in subsequent stages of the study are summarized in Figure 1.

Survey Data Collection. In February 2004, we sent a mailed questionnaire to a random sample of 7,000 of the 31,959 members who met inclusion criteria. This initial survey asked about: family history (all blood relatives who had been diagnosed with colorectal cancer, their relationship to the respondent, and their age(s) of onset); screening history, including whether their physician had ever asked if a family member had colon or rectal cancer or had recommended screening; and demographic characteristics. We sent a reminder post card to all nonresponders 2 months after the initial mailing and closed this phase of data collection 6 months after the surveys were first mailed. None of the responding patients met usual criteria for the autosomal dominant syndromes, Hereditary Nonpolyposis Colon Cancer and Familial Adenomatous Polyposis, which are associated with an unusually high risk of colorectal and (in the case of HNPCC) other cancers and more aggressive screening than in patients with a simple family history.

Six months after we sent the initial survey, we mailed a followup survey to the 355 patients who had reported a family history of colorectal cancer, and a random sample of 710 who had not reported a family history, on the initial survey. We chose an interval of 6 months between surveys to allow enough time for responses to the initial survey and to minimize the effect of the first survey on responses to the second. The follow-up questionnaire asked about patients' knowledge of colorectal cancer prevention in general, whether they believed it runs in families, their perception of their own risk, knowledge of screening tests, their own colorectal cancer screening history, their intentions for screening in the future, and attributes of screening tests that mattered most to them. Questions were adapted from existing, validated instruments. ${ }^{9-12}$ We resent the survey to patients who

Table 1. Characteristics of Respondents to the Initial Survey and Comparison to Nonrespondents

\begin{tabular}{|c|c|c|c|c|}
\hline \multirow[t]{2}{*}{ Characteristic } & \multicolumn{2}{|c|}{$\begin{array}{l}\text { Respondents } \\
(N=1,870)\end{array}$} & \multicolumn{2}{|c|}{$\begin{array}{l}\text { Nonrespondent } \\
(N=4,937)^{*}\end{array}$} \\
\hline & Number $^{\dagger}$ & $\%$ & Number & $\%$ \\
\hline \multicolumn{5}{|l|}{ Age (years) ${ }^{\ddagger}$} \\
\hline $35-39$ & 260 & 13.9 & 984 & 19.9 \\
\hline $40-44$ & 362 & 19.4 & 1,199 & 24.3 \\
\hline $45-49$ & 480 & 25.7 & 1,280 & 25.9 \\
\hline $50-55$ & 766 & 41.0 & 1,474 & 29.9 \\
\hline \multicolumn{5}{|l|}{$\mathrm{Sex}^{\ddagger}$} \\
\hline Female & 1,129 & 60.4 & 2,572 & 52.1 \\
\hline Male & 739 & 39.6 & 2,365 & 47 \\
\hline \multicolumn{5}{|l|}{ Race/ethnicity ${ }^{*}$} \\
\hline Caucasian & 1,138 & 86.6 & 2,120 & 72.0 \\
\hline Black & 139 & 10.6 & 621 & 21.1 \\
\hline Asian & 16 & 1.2 & 72 & 2 \\
\hline Hispanic & 21 & 1.6 & 129 & 4. \\
\hline Native American & 0 & 0 & 1 & \\
\hline \multicolumn{5}{|l|}{ Education } \\
\hline Some high school & 25 & 1.3 & & \\
\hline GED or HS diploma & 128 & 6.8 & & \\
\hline Some college courses & 276 & 14.8 & & \\
\hline College degree & 1,439 & 77.0 & & \\
\hline \multicolumn{5}{|l|}{ Household income (\$) } \\
\hline$<20,000$ & 24 & 1.3 & & \\
\hline $20,000-34,000$ & 77 & 4.1 & & \\
\hline $35,000-49,000$ & 154 & 8.2 & & \\
\hline $50,000-74,000$ & 415 & 22.2 & & \\
\hline$>75,000$ & 1119 & 59.8 & & \\
\hline
\end{tabular}

*Education and household income were obtained from the survey and are not available for nonrespondents

${ }^{\dagger}$ Numbers do not total 1,870 in some rows because of missing data

${ }^{\ddagger} P$ value for respondents versus nonrespondents $\leq .001$ 
Table 2. Prevalence of Family History of Colorectal Cancer Age 35 - 55 Years According to Strength of Risk $\left(N=1,854^{*}\right)$

\begin{tabular}{|c|c|c|c|}
\hline $\begin{array}{l}\text { Strength of } \\
\text { History }\end{array}$ & Definition & $\begin{array}{l}\text { Number of } \\
\text { patients }\end{array}$ & Percentage \\
\hline Strong & $\begin{array}{l}\text { 1st degree relative with } \\
\text { onset at age } \leq 60 \text { years } \\
\text { or } 2 \text { or more } 1 \text { st degree } \\
\text { relatives at any age }\end{array}$ & 53 & 2.9 \\
\hline Intermediate & $\begin{array}{l}\text { 1st degree relative with } \\
\text { onset at age } 60 \text { or } \\
\text { more years or } 2 \text { or } \\
\text { more } 2 \text { nd degree } \\
\text { relatives }\end{array}$ & 162 & 8.7 \\
\hline Other & $\begin{array}{l}\text { Other family history } \\
\text { of colorectal cancer }\end{array}$ & 140 & 7.6 \\
\hline None & $\begin{array}{l}\text { No family history of } \\
\text { colorectal cancer }\end{array}$ & 1,499 & 80.9 \\
\hline Total & & 1,854 & 100.1 \\
\hline
\end{tabular}

*Twelve patients responded to the initial survey but did not provide complete information on family history of colorectal cancer

had not responded within 3 weeks and included in this study all responses received within 4 months of the initial mailing.

Medical Record Review. To assess whether, when, and how patients had been screened, we searched the electronic medical records of all patients who returned the follow-up survey for a set of codes for screening for colorectal cancer by fecal occult blood test, sigmoidoscopy, colonoscopy, and barium enema recorded in the 10 years before the initial survey. Patient self-reports were not used as the standard for whether screening took place.

Of 833 participants who completed the follow-up survey, 373 gave permission for us to review their medical records specifically for family history. To assess whether family history had been recorded in the medical record, we performed a text word search on the 357 of these 373 records we could locate (96\%). We created an algorithm that included the presence of various synonyms for family, relatives, or their abbreviations as well as synonyms or their abbreviations for colorectal cancer, both recorded in the same visit. The algorithm also identified patients who had the code for "family history of colorectal cancer" in their problem list. The algorithm flagged 163 of the 357 available records as containing family history information. One of us (RF) reviewed all flagged records and coded family history as present in the medical record if the review confirmed the algorithm. All records not flagged by the algorithm, or flagged incorrectly (relative to the review) as positive were coded as not containing a family history of colorectal cancer.

Definitions of Variables. We grouped respondents' strength of family history into one of four mutually exclusive categories: strong, intermediate, weak, and no family history (see Table 2 for definitions). These categories are consistent with the risk stratification recommended in current clinical practice guidelines. $^{3}$

We defined appropriate screening tests according to local (HVMA) guidelines: for strong family history, colonoscopy beginning at age 40 and repeated every 5 years; for intermediate family history, screening beginning at age 40 years with flexible sigmoidoscopy every 5 years and fecal occult blood test (FOBT) every year, colonoscopy every 10 years, or double contrast barium enema every 5 years; for weak or no family history, these same tests, at the same interval as for intermediate risk patients, but starting at age 50 years. The local standards were comparable to national guidelines for patients with family history of colorectal cancer but more stringent for average risk patients, for whom either FOBT or sigmiodoscopy, not necessarily both, are usually recommended. We took three FOBTs in 5 years to be adequate screening, instead of one every year, to allow for the common practice of scheduling FOBTs after each year's anniversary.

Statistical Analyses. Data from surveys and medical records were linked and analyzed using SAS version 8.2. The main results were descriptive statistics and contingency tables relating screening experiences to strength of family history and age. Analyses of screening took into account the recommended interval between screening examinations and how choice of test and interval differed according to strength of family history. The Chi-square statistic was used to calculate $P$-values for proportions the binomial distribution to estimate confidence intervals.

\section{RESULTS}

We sent initial surveys to 7,000 patients, 193 of which were returned because of wrong addresses. Of the remaining 6,807 , 1,870 were returned, for a response rate of $27.5 \% ; 1,854$ provided adequate family history information. Of the 1,065 members sent the follow-up survey, $833(78.2 \%)$ returned useable surveys. Excluding 66 patients who declined further participation in the study, 372 of 767 (48.5\%) asked gave permission to review their medical records for family history information. Figure 1 summarizes the number of patients participating at each stage of this study.

The characteristics of respondents to the initial survey are summarized in Table 1 and compared with patients in the original sample who did not respond. Respondents were more likely to be older, female, and white. The demographic characteristics of respondents to the follow-up survey were similar to those of respondents to the initial survey.

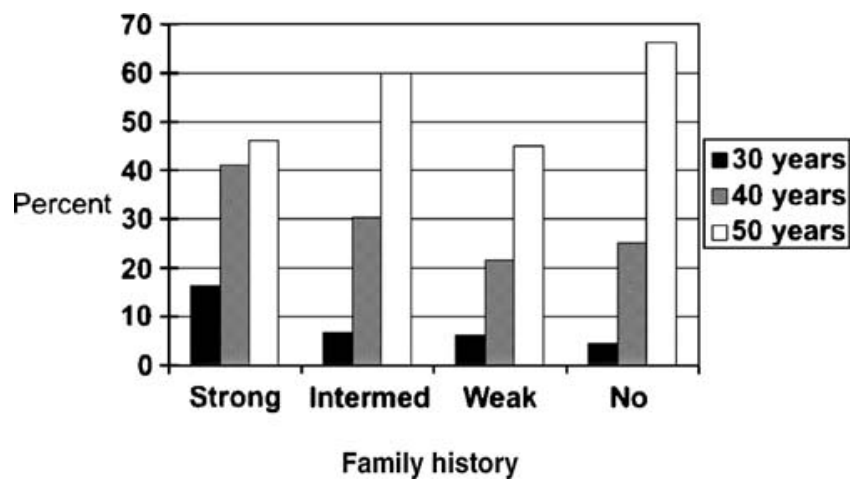

Figure 2. Age at which respondents thought they should begin screening for colorectal cancer according to strength of family history $(N=833)$. 


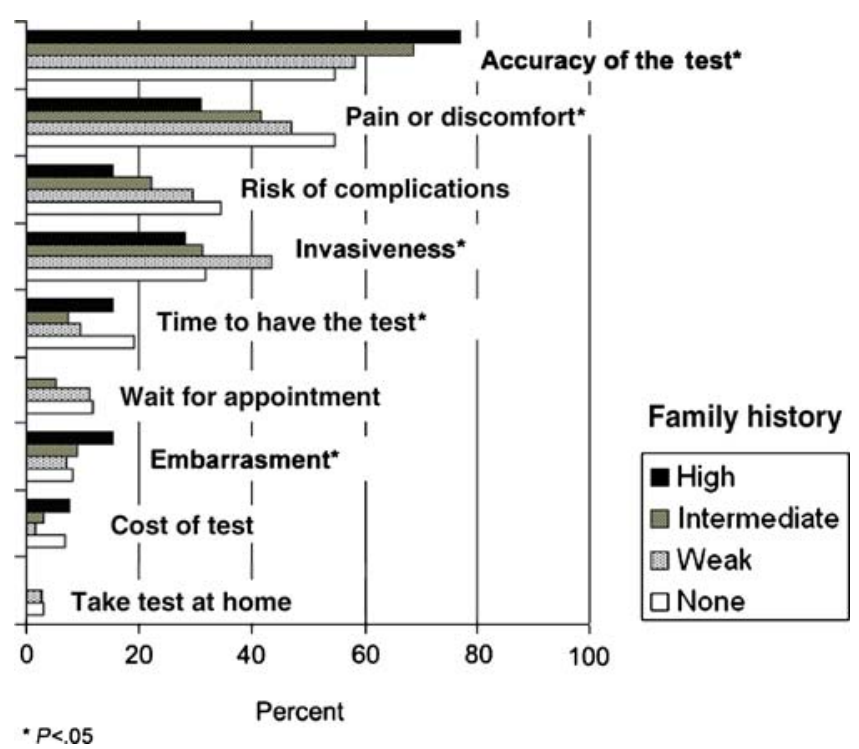

Figure 3. Screening test characteristics that matter most to patients, in order of importance, according to strength of family history $(N=825)$.

Family History Prevalence. Of 1,854 respondents, 355 (19.1\%) reported a family history of colorectal cancer (Table 2). Family history was clinically important in the $11.6 \%$ with strong or intermediate strength history, in that, according to guidelines, it should have prompted screening before age 50 years. The prevalence of clinically important family history, increased with the age of the respondent, from $4.7 \%$ for patients aged $35-39$ years to $18.6 \%$ by age 55 years $(P<0.001)$. For a substantial proportion of patients with a family history of colorectal cancer in our sample, this risk factor would have become apparent only after age 50 , too late to implement recommendations for early screening.

Beliefs. Beliefs about colorectal cancer differed according to strength of family history but not age. Over $97 \%$ of respondents reporting a family history of colorectal cancer, regardless of strength of the history, believed that "colon cancer is a type of cancer that runs in families" while fewer (75\%) of those who did not report colorectal cancer in their own family agreed. Over half of respondents with a clinically important (strong or intermediate strength) family history (59\% in both groups) thought that they were more likely to get colon cancer compared with other people of the same age and race, whereas few respondents without a family history of colorectal cancer (less than 5\%, regardless of age) believed they were at increased risk. Most patients with a family history agreed with the assertion that "family and friends think I should be screened for colon cancer." This belief was directly related to strength of family history and was strongest $(95 \%$ agreement) in respondents with a strong family history who were under age 50 years.

Many patients with a family history of colorectal cancer did not know that they should begin screening earlier than average risk patients (Fig. 2). Almost half of respondents in the strong risk category $(18 / 39=46 \%)$ incorrectly believed that they should begin screening at age 50 years, whether or not they were themselves over 50 years old. On the other hand, a substantial proportion of respondents with no family history of colorectal cancer believed they should be screened before age 50 years: $24.9 \%$ of average risk respondents believed they should begin screening at age 40 years and $4.5 \%$ thought they should begin screening at age 30 years

Identification of Risk. Of 1,041 respondents younger than age 50 years, 407 (39.1\%, 95\% CI 36.1\%, 42.0\%) reported that their clinician had asked if a family member had colon or rectal cancer. In contrast, $72.2 \%$ (95\% CI 70.0, 76.4) of respondents age 50 years or older said they had been asked.

Appropriate Screening. For the 29 persons with a strong family history who were less than 50 years old, 13 (45\%) were screened before age 50 years with colonoscopy. Screening rates in patients with a strong family history were higher $(18 / 24,75 \%)$ over age 50 years ( $P$ for difference in screening rates by age=0.03). A similar pattern was seen for patients with an intermediate strength family history: only 16 of 69 (23\%) under age 50 had been screened appropriately, whereas 71 of $93(76 \%)$ patients age 50 years or older had been screened $(P<0.001)$. When patients with strong or intermediate family history of colorectal cancer were screened before age 50 years, it was predominantly with colonoscopy. For patients 50-55 years old, appropriate screening rates were similar for patients with weak and with no family history ( 49 and $41 \%$, respectively, $P=0.10$ ).

Agreement Between Patients' Reports of Family History and Medical Records. Among the 357 study patients who gave permission for us to examine their medical records, 136 had reported a family history of colorectal cancer on the survey and 80 of these had that information recorded in their electronic medical record. Taking patient report as the "gold standard" for accuracy, review of the medical record had a sensitivity of $59 \%$ and a specificity of $95 \%$ for detecting this family history. One of the authors (MB) interviewed patients who had not reported family history of colorectal cancer on the survey but had this history recorded in their medical record. Most (eight out of ten) still thought that they did not have a family history of colorectal cancer and could explain why family history was (incorrectly) mentioned in the medical record.

If family history was mentioned in the medical record at all, it was likely to be accompanied by information about the relative's relationship $(86 / 90=96 \%)$ but less likely to include information about the relative's age of onset $(49 / 90=54 \%)$. This additional information was no more or less likely to be present in patients with high and intermediate risk than in those with weak family history of colorectal cancer.

Screening Test Preference. We asked patients to choose three of nine test characteristics that mattered most to them. Regardless of family history, respondents chose, in descending order of importance: accuracy, pain and discomfort, risk of complications, invasiveness, time for the procedure, waiting time, embarrassment, cost, and doing the test at home (Fig. 3). Respondents with a strong or intermediate family history of colorectal cancer believed that accuracy mattered more and 
pain, invasiveness, and embarrassment mattered less compared with patients with weak or no such family history $(P$ for each comparison $<.05$ ).

\section{DISCUSSION}

The study setting has many characteristics that are believed to favor screening. Nevertheless, most respondents had not been asked about family history of colorectal cancer in time to begin screening if that history were present. Patients with a strong family history of colorectal cancer generally knew that this cancer runs in families, believed they were at increased risk, and thought that family and friends wanted them to be screened, but did not know that screening should begin before age 50 years. A review of electronic medical records would not have detected many of the patients at increased risk because the relevant data were not recorded. It is not surprising then that only half the patients with a strong family history were screened appropriately.

Our study adds to a small literature on patient preferences for colorectal cancer screening tests. ${ }^{13-16}$ We found, as Ling did, ${ }^{13}$ that accuracy and discomfort were most important whereas inconvenience was less important to patients. Respondents with a strong or intermediate family history expressed similar preferences but accuracy was even more important and pain, risk of complications, and invasiveness less important to them. These are distinguishing characteristics of colonoscopy, the test recommended for such patients, suggesting that recommendations are consistent with patients' preferences, perhaps increasing the likelihood of adherence. We had little opportunity to explore the effect of costs on preferences, as Pignone did, ${ }^{14}$ because most respondents in our study were insured for all screening test options.

The shortfalls we observed are consistent with direct observation of care by primary care physicians in the community ${ }^{17}$ and with studies of physicians' knowledge, beliefs, and stated practices. ${ }^{18-20}$ Barriers to family history taking in primary care have been described, including lack of time, reimbursement policies that are inconsistent with this activity, and clinicians' perceptions that their knowledge and skills are not up to date $^{8,21}$, and these may have accounted for some of our findings.

Response rate to the initial survey was relatively low and respondents were a biased sample of the underlying population, in that they were older and more often female and white. As a result, our estimates of family history prevalence, as well as patients' beliefs, preferences, and care might have misrepresented those of less selected adults in our setting. It is reassuring in this regard that the prevalence of family history found in our study was similar to that found in studies of the general population $^{22}$ and in the PLCO trial. ${ }^{23}$ Nevertheless, we cannot rule out the possibility that selection bias affected our results nor can we estimate the magnitude and direction of potential bias.

Our study had several other limitations. We did not ask about family history of colorectal adenomas, also a risk factor for colorectal cancer. ${ }^{24}$ We did not measure comorbidity, a reason for not pursuing screening in some patients. Although we searched medical records for 10 years before the initial survey, some colonoscopies may have been missed in patients who had not been in the practice beyond 5 years. We did not validate patients' reports of family history against external sources, such as hospital records and the death certificates; however, patients' reports of family history of colorectal cancer have been shown to be relatively accurate. ${ }^{25}$ The initial survey may have affected responses to the follow-up survey, especially for participants with a family history, although the two surveys were 6 months apart.

On the other hand, the study has important strengths. By stratifying results by strength of risk and by age, we were able to examine effects at the level of specificity set out in most clinical practice guidelines. Also, we were able to describe patients' attitudes, knowledge, and beliefs in relation to the level of their familial risk and screening. We could rely on medical record data when determining screening practices.

More attention to family history and more effective ways of integrating it into practice are needed. ${ }^{26,27}$ Whatever gains are made for familial colorectal cancer should be applicable to other conditions, such as breast and prostate cancer, cardiovascular disease, and diabetes, for which risk in adult life and screening practices also depend on whether close relatives have developed these conditions at a relatively early age.

Acknowledgments: This work was supported by grant No. 1 R21 CA102381-01 from the National Cancer Institute, National Institutes of Health.

Conflicts of Interest: None disclosed.

Corresponding Author: Robert H. Fletcher, MD, MSc; 208 Boulder Bluff, Chapel Hill, NC 27516, USA (e-mail: Robert_Fletcher@hms. harvard.edu).

\section{REFERENCES}

1. U.S. Preventive Services Task Force. Screening for colorectal cancer: recommendations and rationale. Ann Intern Med. 2002;137:129-31.

2. Smith RA, Cokkinides V, Eyre HJ. American Cancer Society guidelines for the early detection of cancer, 2005. CA Cancer J Clin. 2005;55:31-44.

3. Winawer S, Fletcher RH, Rex D, et al. Colorectal cancer screening and surveillance: clinical guidelines and rationale-update based on new evidence. Gastroenterology. 2003;124:544-60.

4. Centers for Disease Control and Prevention (CDC). Increased use of colorectal cancer tests-United States, 2002 and 2004. Morb Mort Wkly Rep. 2006;55:308-11.

5. Johns LE, Houlston RS. A systematic review and meta-analysis of familial cancer risk. Am J Gastroenterol. 2001;96:2992-3003.

6. Slattery ML, Kerber RA. Family history of cancer and colon cancer risk: the Utah Population Database. J Natl Cancer Inst. 1994;86:1618-26.

7. Fuchs CS, Giovannucci EL, Colditz GA, Hunter DJ, Speizer FE, Willett WC. A prospective study of family history and the risk of colorectal cancer. New Engl J Med. 1994;331:1669-74.

8. Rich EC, Burke W, Heaton CJ, et al. Reconsidering the family history in primary care. J Gen Intern Med. 2004;19:273-80.

9. Jacobs LA. Health beliefs of first-degree relatives of individuals with colorectal cancer and participation in health maintenance visits: a population-based survey. Cancer Nurs. 2002;25:251-65.

10. Lipkus IM, Samsa GP, Dement $\mathbf{J}$, et al. Accuracy of self-reports of fecal occult blood tests and test results among individuals in the carpentry trade. Prev Med. 2003;37:513-9.

11. Rakowski W, Fulton JP, Feldman JP. Women's decision making about mammography: a replication of the relationship between stages of adoption and decisional balance. Health Psychol. 1993;12:209-14.

12. Vernon SW, Myers RE, Tilley BC. Development and validation of an instrument to measure factors related to colorectal cancer screening adherence. Cancer Epidemiol Biomarkers Prev. 1997;6:825-32.

13. Ling BS, Moskowitz MA, Pearson B, Schroy Paul C III. Attitude toward colorectal cancer screening tests. A survey of patients and physicians. J Gen Intern Med. 2001;16:822-30. 
14. Pignone M, Bucholtz D, Harris R. Patient preferences for colon cancer screening. J Gen Intern Med. 1999;14:432-7.

15. Leard LE, Savides TJ, Ganiats TG. Patient preferences for colorectal cancer screening. J Fam Pract. 1997;45:211-8.

16. Wolf RL, Basch CE, Brouse CH, Shmukler C, Shea S. Patien preferences and adherence to colorectal cancer screening in an urban population. Am J Public Health. 2006;96:809-11.

17. Acheson LS, Weisner GL, Zyzanski SJ, Goodwin MA, Stange KC. Family history-taking in community family practice: implications for genetic screening. Genet Med. 2000;2(3):180-5.

18. Schroy PC 3rd, Barrison AF, Ling BS, Wilson S, Geller AC. Family history and colorectal cancer screening: a survey of physician knowledge and practice patterns. Am J Gastroenterol. 2002;97:1013-6.

19. Acton RT, Burst NM, Casebeer L, et al. Knowledge, attitudes, and behaviors of Alabama's primary care physicians regarding cancer genetics. Acad Med. 2000;75:850-2.

20. Hayflick SJ, Eiff MP, Carpenter L, Steinberger J. Primary care physicians' utilization and perceptions of genetic services. Genet Med. $1998 ; 1: 13-21$
21. Suther S, Goodson P. Barriers to the provision of genetic services by primary care physicians: a systematic review of the literature. Genet Med. 2003;5:70-6.

22. Michell RJ, Campbell H, Farrington SM, Brewster DH, Porteus ME, Dunlop MG. Prevalence of family history of colorectal cancer in the general population. Br J Surg. 2005;92:1161-4.

23. Pinsky PF, Kramer BS, Reding D, Buys S, for the PLCO Project Team. Reported family history of cancer in the prostate, lung, colorectal cancer, and ovarian cancer screening trial. Am J Epidemiol. 2003;157:792-9.

24. Winawer SJ, Zauber AG, Gerdes H, et al. Risk of colorectal cancer in families of patients with adenomatous polyps. N Engl J Med. 1996; 334:82-7.

25. Murff HJ, Spigel DR, Syngal S. Does this patient have a family history of cancer? An evidence-based analysis of the accuracy of family cancer history. JAMA. 2004;292:1480-9.

26. Guttmacher AE, Collins FS, Carmona RH. The family history-more important than ever. N Engl J Med. 2004;351:2333-6.

27. Burke w. Taking family history seriously. Ann Intern Med. 2005; 143:388-9. 